\title{
Farklı Dozlarda Intraperitoneal 5-Fluorouracil Kullanımının Deneysel Intestinal Anastomozların İyileşme Süresi Üzerine Etkileri*
}

\author{
Veysi Hakan YARDIMCI**
}

\section{$\ddot{\mathbf{O} z}$}

Amaç: Kolorektal cerrahinin en önemli komplikasyonu anastomoz ayrılması veya kaçaktır. Lokal ve sistemik pek çok faktörün kolon anastomozlarının iyileşme sürecinde ve anastomoz kaçaklarının oluşmasında etkili olduğu bilinmektedir. Bu faktörlerden bir tanesi de kemoterapidir. Gastrointestinal sistem kanserlerinde başarılı sonuçlar alabilmek için cerrahi yöntem ile kemoterapi ve radyoterapi arasındaki hassas dengeyi bulabilmek şarttır.

Yöntem: Çalışmada gastrointestinal sistem (GİS) kanserlerinde en çok kullanılan sitostatik 5Fluorouracil (5-FU) intraperitoneal uygulanması araştırılmıştır. Bu amaçla 42 adet Wistar Albino cinsi dişi sıçan her biri eşit sayıda denek içeren kontrol grubu (Intraperitoneal $\mathrm{NaCl}$ ), tek doz 5Fluorouracil grubu (Intraperitoneal $20 \mathrm{mg} / \mathrm{kg} /$ gün 5 -FU) ve multipl doz 5 -Fluorouracil grubu (Intraperitoneal $20 \mathrm{mg} / \mathrm{kg} /$ gün 5-FU 3 gün art arda) olmak üzere üç ana gruba ayrılmıştır. Her ana gruptaki 14 deneğin yarısı 3. günde, diğer yarısı ise 7. günde sakrifiye edilerek alt gruplar elde edilmiştir. 5-FU'in yan etkilerini incelemek amacıyla lökosit ve albümin değerleri araştırılmıştır. Anastomoz iyileşmesinin gruplar arasındaki farklılıklarını değerlendirmek için ise patlama basıncı, hidroksiprolin düzeyi ve histopatolojik parametreler kullanılmıştır.

\footnotetext{
Özgün Araştırma Makalesi (Original Research Article)

Geliş / Received: 04.05.2020 \& Kabul / Accepted: 27.11.2020

DOI: https://doi.org/10.38079/igusabder.731424

* Bu çalışma, İstanbul Üniversitesi, Cerrahpaşa Tıp Fakültesi, Genel Cerrahi Anabilim Dalı’nda Prof. Dr. Tarık AKÇAL danışmanlığında hazırlanmış ve 1996 yılında kabul edilmiş "Farklı Dozlarda Intraperitoneal 5-Fluorouracil Kullanımının Deneysel Intestinal Anastomozların İyileşme Süresi Üzerindeki Etkileri (Deneysel Çalışma)" başlıklı uzmanlık tezinden üretilmiștir; ilgili tez, 1996 Ulusal Cerrahi Kongresi'nde 15-19 Mayıs 1996'da sözlü bildiri olarak sunulmuş, kongre bildiri kitabında özeti yayınlanmıştır.

** Dr. Öğr. Üyesi, İstanbul Gelişim Üniversitesi, Sağlık Hizmetleri Meslek Yüksekokulu, Hemşirelik Bölümü, İstanbul, Türkiye, E-posta: hakanyardimci@yahoo.com

ORCID https://orcid.org/o000-0003-1395-3882
} 
Bulgular: Cerrahi girişim sonrası batın içi yapışıklıklar açısından 5-FU uygulamasının kontrol grubu ile karşılaştırılmasında istatistiksel açıdan anlamlı fark bulunmadı ( $>$ > 0,05). Albümin ve lökosit değerlerinde; kontrol gruplarına göre 5-FU kullanılan gruplarda istatistiksel olarak anlamlı düşük sonuçlar elde edildi $(\mathrm{p}<0,05)$. Anastomoz iyileşmesinin değerlendirilmesinde patlama basıncı, histopatolojik inceleme sonuçları multipl doz 5-FU kullanılan gruplarda tek doz 5-FU ve kontrol gruplarına göre istatistiksel olarak anlamlı düşük skorlar gösterdi $(p<0,05)$.

Sonuç: Erken postoperatif dönemde başlanan multipl olarak verilen yüksek doz intraperitoneal 5-FU tedavisinin anastomoz iyileşmesini geciktirerek negatif etki gösterdiği, buna karşın sınırlı dozlarda uygulanan intraperitoneal 5 -FU'in anastomoz iyileşmesi üzerinde hiçbir negatif etki göstermeyip kontrol grupları ile paralel iyileşme gösterdiği yönündedir. Deneysel çalışmadan elde edilen bu veriler ışı̆̆ında; klinik uygulamada şimdiye kadar korkulan ve geç başlanan kemoterapinin, sınırlı dozlarda erken postoperatif dönemde de kullanım alanı bulabileceği söylenebilir.

Anahtar Sözcükler: 5-Florourasil, anastomoz, bölgesel perfüzyon kanser kemoterapisi.

\title{
The Effects of Intraperitoneal 5-Fluorouracil Use at Different Doses on the Recovery Time of Experimental Intestinal Anastomoses
}

\begin{abstract}
Aim: The most important complication of colorectal surgery is the separation of anastomosis or leakage. It is known that many local and systemic factors are effective in the healing process of colon anastomoses and in the formation of anastomotic leaks. One of these factors is chemotherapy. In order to achieve successful results in gastrointestinal system cancers, it is necessary to find the sensitive balance between the surgical method and chemotherapy and radiotherapy.

Method: In our study, intraperitoneal administration of the most commonly used cytostatic 5Fluorouracil (5-FU) in gastrointestinal tract cancers was investigated. For this purpose, 42 female Wistar Albino rats were divided into three main groups, each containing an equal number of subjects. Groups are Control group (Intraperitoneal $\mathrm{NaCl}$ ), single dose 5-Fluorouracil group (Intraperitoneal $20 \mathrm{mg} / \mathrm{kg} /$ day 5-FU) and multiple dose 5-Fluorouracil group (Intraperitoneal 20 $\mathrm{mg} / \mathrm{kg} /$ day 5 -FU 3 days consecutively). Half of the 14 subjects in each main group were sacrificed on the 3 rd day and the other half on the 7 th day. Leukocyte and Albümin values were investigated for the purpose of examining the side effects of 5 -FU. Bursting pressure, hydroxyproline level and histopathologic parameters were used to assess the differences in anastomotic healing between groups.
\end{abstract}


Results: There was no statistically significant difference in comparison with the control group of the chemotherapeutic 5-FU application in terms of intra-abdominal adhesions after surgical intervention ( $p>0,05)$. Albümin and leukocyte values; According to the control groups, statistically significant low results were obtained in groups used in 5 - $\mathrm{FU}(\mathrm{p}<0,05)$. Bursting pressure, histopathologic examination results in the evaluation of anastomotic healing; Multiple doses of 5 -FU showed statistically significant low scores in groups with a single dose of 5 -FU and control groups $(\mathrm{p}<0,05)$.

Conclusion: The impression obtained from the study showed that the high dose intraperitoneal 5 -FU treatment, which was started in the early postoperative period, had a negative effect by delaying the anastomotic healing, but in limited doses Intraperitoneal 5-FU does not show any negative effects on anastomotic healing and is in parallel with control groups. In the light of this data from our experimental work; In clinical practice, it can be said that the chemotherapy, which has been feared and started late, may also find the usage area in the early postoperative period in limited doses.

Keywords: 5-Fluorouracil, anastomosis, regional perfusion cancer chemotherapy.

\section{Giriş}

Gastrointestinal sistem (GİS) kanserlerinde küratif cerrahi tedavi tek başına başarısız kalmaktadır. Bunun nedeni olarak; ameliyat öncesi karaciğer ve periton tutulumu, rezeksiyon sırasında travmaya bağlı olarak bölgesel tümör hücresi implantasyonu, tümör hücrelerinin lenf drenajı ve kan yolu ile yayılması, intralüminal tümör hücrelerinin rezeksiyon sirasında implantasyonu sayılabilir ${ }^{1-4}$.

Kemoterapi ve radyoterapi, GİS kanserlerinin cerrahi tedavisine tamamlayıcı yöntemler olarak gösterilir. Son yıllarda sitostatiklerin intraperitoneal yolla batın içi serbest tümör hücrelerine etkili olduğu ve aynı zamanda, intraperitoneal yoldan verilen sitostatiklerin kısa bir süre içinde portal vene geçerek karaciğer metastazlarına da etki gösterdiği bildirilmiştir ${ }^{1,5}$.

Kanser tedavisinde multidisipliner yaklaşımla daha ümit verici sonuçların elde edilmeye başlanması cerrahi girişim ve antineoplastik ilaç tedavisinin birlikte veya yakın aralıklarla kullanımını gündeme getirmiştir6-8. Preoperatif dönemde rezektabilite şansını arttırmak amacıyla uygulanan neoadjuvan kemoterapiye olan ilgi giderek 
artarken, postoperatif adjuvan kemoterapi bugün birçok tümör için standart tedavi olarak uygulanmaktadır9. Öte yandan ameliyat sırasında tümör hücrelerinin dolaşıma geçmesiyle metastaz olasılığının arttığı, bunun ise intraoperatif ve erken postoperatif dönemdeki kemoterapi uygulaması ile azaltılabileceği gösterilmiştir ${ }^{8}$. Ancak kemoterapinin yara iyileşmesini olumsuz yönde etkileyerek geciktireceği inancı, genellikle iyileşme tamamlandıktan sonra ilaç tedavisine başlama eğilimine yol açmıştır.

Klinik uygulamada kemoterapötiklerin yara iyileşmesini bozacağına ilişkin yayınlar olmasına karşın, tam tersini savunan çalışmalarda mevcuttur6-8,10,11. Aynı şekilde kemoterapötiklerin yara iyileşmesine etkilerini irdeleyen deneysel çalışmaların sonuçları da birbiriyle çelişkilidir ${ }^{12-16}$. Bu çalışmanın amacı, intraoperatif ve postoperatif erken dönemde kemoterapi uygulamasının klinik olarak kolon anastomozu iyileşmesi ve komplikasyon oranında değişikliklere yol açıp açmadı̆̆ını incelemektir. Anastomoz kaçağı, kolon rezeksiyonu sonrası görülen mortalite ve morbiditeye yol açabilen ciddi bir komplikasyondur ${ }^{17-20}$. Özellikle alçakta yapılan sol kolon anastomozları, anastomoz kaçağı açısından yüksek risk taşırlar'18,21-24.

\section{Gereç ve Yöntem}

Çalışmada ağırlıkları 170-200 gr arasında değişen 42 adet Wistar Albino cinsi dişi sıçan kullanılmıştır. Çalışmanın anestezi, cerrahi ve deney protokolleri lokal olarak Hayvan Deneyleri Etik Kurulu (1996-48382) tarafından onaylanmıştır. Tüm deneklerde; eter anestezisi altında steril şartlarda anterior abdominal duvarda yaklaşık $3 \mathrm{~cm}$ uzunluğunda insizyon yapılarak batın boşluğuna girilmiştir. Distal kolon peritoneal refleksyonun yaklaşık $3 \mathrm{~cm}$ proksimalinden rezeke edilmiştir. 6/o Propilen materyal kullanılarak separe sütürler ile tek kat uç uca kolo-kolostomi yapılmıştır.

Denekler, 14 hayvandan oluşan 3 ana gruba ayrılmıştır. Her ana gruptaki 14 deneğin yarısı 3. günde, diğer yarısı ise 7. günde sakrifiye edilerek alt gruplar elde edilmiştir: Grup 1: Multipl doz 5-FU (7. gün sakrifiye) Grup 2: Multipl doz 5-FU (3. gün sakrifiye) Grup 3: Tek doz 5-FU (7. gün sakrifiye) Grup 4: Tek doz 5-FU (3. gün sakrifiye) Grup 5: Kontrol \%o9 $\mathrm{NaCl}$ (7. gün sakrifiye) Grup 6: Kontrol \%o9 NaCl (3. gün sakrifiye)

Çalışmada kemoterapi; 5-FU'in $20 \mathrm{mg} / \mathrm{kg}$ dozuna göre ayarlanmış ve \%o9 $\mathrm{NaCl}$ solüsyonu ile sulandırılarak peroperatuar intraperitoneal verilerek başlanmıştır. Daha sonra batın katları 4/o atravmatik ipek ile kontinü olarak kapatılmıştır. Multipl doz 5- 
FU uygulanacak gruba takip eden günlerde 5 -FU $20 \mathrm{mg} / \mathrm{kg}$ intraperitoneal verilerek, toplam 3 doz elde edilmiştir (6o mg/kg total doz). Gruplardan postoperatif 3. günlerde 7 'şer sıçan eter anestezisi altında sakrifiye edilmiştir. Batın içi ve anastomoz bölgesi makroskobik bulguları kaydedilmiştir. Aynı işlemler postoperatif 7. günlerde tekrarlanmıştır.

Kullanılan 5-FU'in invivo yan etkilerinin tespit etmek için intrakardiyak kan örneği alınmıştır. Lökosit ve albumin değerleri incelenmiştir. Değerler "Variance Analysis" testi ile istatistiksel olarak karşılaştırıldı. Çalışmada anastomoz iyileşmesinin mekanik parametresi olarak barsak patlama basıncı ölçüldü. Biyokimyasal parametre olarak ise hidroksiprolin miktarı tayini yapıldı. Yara iyileşmesindeki oldukça karışık olaylar zincirinin mikroskopik düzeyde histopatolojik incelenmesi yapıldı.

\section{Patlama Basıncı Ölçümü}

Anastomoz bölgesini içeren sol kolon, anastomoz hattının 2-2,5 cm distal ve proksimalinden rezeke edildi. Rezeke edilen kolon segmentinin içindeki feçes \%o9 $\mathrm{NaCl}$ ile temizlendikten sonra distal uç 3/o ipek ile bağlanarak kapatıldı. Kolon segmentinin proksimal ucu bir üçlü musluk yardımı ile lümen içi basıncı ölçebilen manometre ve daha sonra sabit akım pompasına (Perfusor@ Secura FT, B.Braun) bağlandı. Bağırsak parçası, içinde \%o9 $\mathrm{NaCl}$ bulunan bir kapta sabit derinlikte tutulurken sabit akım pompası ile sisteme $100 \mathrm{ml} / \mathrm{h}$ hızla hava verildi. Barsak segmentinde patlamanın belirtisi olan hava kabarcıklarının görünmesi anındaki basınç değeri, manometreden patlama basıncı olarak (mmHg) kaydedildi. Değerler iki yönlü "Variance Analysis" testi ile istatistiksel olarak karşılaştırıldı.

\section{Hidroksiprolin Miktarı Tayini}

Patlama basıncı ölçüldükten sonra, anastomoz hattının $0,5 \mathrm{~cm}$ proksimal ve $0,5 \mathrm{~cm}$ distalini içerecek şekilde kolon parçası histopatolojik tetkik ve hidroksiprolin tayini için kullanıldı. Ağırlıkları tek tek elektronik terazi ile ölçülen doku parçacıkları el homojenizatörü (B.Braun Melsungen AG) kullanılarak belli hacim saf su ile homojenize edildi. Homojenata eşit hacim $\mathrm{HCl}$ katılarak 16-18 saat hidrolize maruz bırakıldı. Hidroliz sonucu asit ortam fenolftalein indikatörünün varlığında $\mathrm{KOH}$ ile nötral pH'a ayarlandı. Renk reaksiyonu için ortama p-dimetilaminobenzaldehit katılarak numunenin ve standartların renklenmesi sağlandı. Oluşan renk ve şiddeti $560 \mathrm{~nm}$ 'de 
spektrofotometrik olarak değerlendirilerek doku örneklerindeki hidroksiprolin miktarı mg/100 mg kuru ağırlıkta doku birimi üzerinden tayin edildi.

\section{Histopatolojik İnceleme}

Parafin kesitler hazırlanarak H\&E ve Masson Trichrome ile boyandı. Preparatlarda her gruptaki yara iyileşmesini değerlendirebilecek; eksüdasyon, iltihabi infiltrasyon, fibroblast aktivasyonu, kollajen yapımı, vaskülarizasyon ve makrofaj agregasyonu gibi kriterler mikroskopik olarak değerlendirildi. Bu değerlendirmede (-) yok, + (az), ++ (orta), +++ (bol), o'dan 6'ya kadar puanlandırıldı.

\section{Bulgular}

Tüm gruplara verilen 5-FU sıçanlar tarafından tolere edildi, anesteziye bağlı ölüm olmadı. Grupların hemen hepsinde anastomoz ile çevre dokular arasında değişik oranlarda, künt diseksiyonla kolay ayrılabilen yapışıklıklar saptandı. Sıçanların hiçbirinde yaygın peritonit şeklinde kendini gösteren makroskopik anastomoz kaçağı saptanmadı. Ancak Grup 2'ye ait 2 adet sıçanda klinik olarak belirti vermeyen minimal anastomoz kaçağı mevcuttu. Bu iki sıçana ait patlama basıncı ölçüm sonuçları (o mmHg) olarak bulunmuştur. Anastomoz etrafinda görülen makroskopik yapışıklıklar, Kappas ve

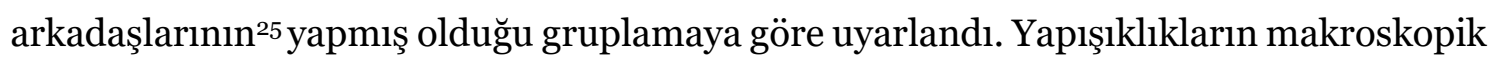
değerlendirilmesinde; Grup 1 ve Grup 2'de görülen yapışıklıkların derecesi diğer gruplara göre yüksek olmasına karşın aralarında istatistiksel olarak anlamlı fark saptanmadı ( $\mathrm{p}>0,05)$ (Tablo 1).

Tablo 1: Anastomoz etrafı yapışıklığın makroskopik değerlendirmesi

\begin{tabular}{|c|c|c|ccccc|c|}
\hline \multirow{2}{*}{ Gruplar } & Yapışıklık & Yapışıklık & \multicolumn{5}{|c|}{ Yapışıklı̆ıı derecesi } & Total denek sayısı \\
& Yok & Var & $\mathbf{0}$ & $\mathbf{1}$ & $\mathbf{2}$ & $\mathbf{3}$ & $\mathbf{4}$ & \\
\hline Grup 1 & - & 7 & - & - & - & 6 & 1 & 7 \\
Grup 2 & - & 7 & - & - & - & 6 & 1 & 7 \\
Grup 3 & - & 7 & - & - & 2 & 5 & - & 7 \\
Grup 4 & - & 7 & - & - & 3 & 4 & - & 7 \\
Grup 5 & 1 & 6 & 1 & - & 2 & 4 & - & 7 \\
Grup 6 & 1 & 6 & 1 & 1 & 2 & 3 & - & 7 \\
\hline
\end{tabular}

o: Yapışıklık yok, 1: Hafif derece yapışıklık (1-3 tane fibröz bant), 2: Orta derece yapışıklık (3'den fazla fibröz bant veya 1 intestinal segmente yapışıklık), 3: Belirgin derece yapışıklık (l'den fazla intestinal segmente yapışılklık), 4: Masif yapışıklık (Yapışıklığa diğer etraf organlar da katılmış). 
Üç ana grupta ortalama patlama basıncı değerleri (ort \pm SD) Grup 1 ve 2'de 9,0 $\pm 5,4$; Grup

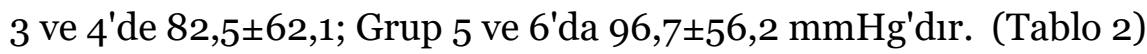

Ana gruplar dikkate alınarak değerler karşılaştırıldığında; Grup 1 ve 2 ile Grup 3 ve 4, Grup 5 ve 6 arasındaki fark anlamlı derecede düşük bulundu (p<0,05). Grup 3 ve 4 ile Grup 5 ve 6 arasında benzer şekilde istatistiksel fark bulunmadı (p>0,05) (Tek yönlü ANOVA).

Patlama basıncı değerleri için; gruplar veya sakrifiye edilen günler ayrı ayrı dikkate alındı ̆̆ında aralarındaki farklar istatistiksel olarak anlamlıdır ( $\mathrm{p}<0,05)$. Patlama basıncı değerleri multipl doz 5-FU kullanılan gruplarda, tek doz 5-FU ve kontrol gruplarına göre anlamlı düşük değerler bulunmuştur.

Tablo 2: Grupların patlama basıncı değerleri (mmHg)

\begin{tabular}{|c|c|c|c|c|c|c|}
\hline \multirow[b]{2}{*}{ Denek No } & \multicolumn{2}{|c|}{ Multipl doz 5-FU } & \multicolumn{2}{|c|}{ Tek doz 5-Fu } & \multicolumn{2}{|c|}{ Kontral } \\
\hline & $\begin{array}{c}\text { Grup } 1 \\
\text { Multipl doz } \\
\text { 7.gün } \\
\end{array}$ & $\begin{array}{c}\text { Grup } 2 \\
\text { Multipl doz } \\
\text { 3.gün }\end{array}$ & $\begin{array}{l}\text { Grup } 3 \\
\text { Tek doz } \\
7 \text {.gün }\end{array}$ & $\begin{array}{l}\text { Grup } 4 \\
\text { Tek doz } \\
\text { 3.gün }\end{array}$ & $\begin{array}{l}\text { Grup } 5 \\
\text { Kontrol } \\
7 \text {.gün }\end{array}$ & $\begin{array}{l}\text { Grup } 6 \\
\text { Kontrol } \\
\text { 3.gün }\end{array}$ \\
\hline 1 & 20 & 5 & 160 & 15 & 98 & 50 \\
\hline 2 & 10 & $\mathrm{O}$ & 125 & 20 & 108 & 45 \\
\hline 3 & 5 & 10 & 148 & 34 & 136 & 52 \\
\hline 4 & 12 & 10 & 168 & 28 & 186 & 42 \\
\hline 5 & 8 & $\mathrm{O}$ & 142 & 32 & 170 & 54 \\
\hline 6 & 12 & 8 & 134 & 24 & 166 & 50 \\
\hline 7 & 15 & 12 & 108 & 18 & 160 & 38 \\
\hline Ort $\pm S D$ & $11.7 \pm 4.49$ & $6.4 \pm 4.53$ & $140 \pm 19.02$ & $24.4 \pm 6.67$ & $146.2 \pm 30.75$ & $47.2 \pm 5.36$ \\
\hline
\end{tabular}

Ana gruplar dikkate alınarak lökosit değerleri açısından karşılaştırma yapıldı̆̆ında; (Tablo 3) (Tek yönlü-ANOVA) Grup 1 ve 2 ile Grup 3 ve 4, Grup 5 ve 6 arasindaki fark anlamlı derecede düşük bulundu (p<0,05). Ayrıca Grup 3 ve 4 ile Grup 5 ve 6 arasındaki fark da anlamlı derecede düşük bulundu $(\mathrm{p}<0,05)$.

Lökosit değerleri için; gruplar dikkate alındığında aralarındaki fark istatistiksel olarak anlamlıdır ( $\mathrm{p}<0,05)$. Sakrifiye edilen günler dikkate alındığında ise lökosit değerleri arasında anlamlı fark saptanmadı (p>0,05) (çift yönlü-ANOVA). Lökosit değerlerinde 5FU kullanılan gruplarda, kontrol gruplarına göre anlamlı bir azalma tespit edilirken, 5FU'in multipl ve tek doz kullanımı arasında da anlamlı azalma görüldü. 
Tablo 3: Grupların lökosit değerleri (.../mm3)

\begin{tabular}{|c|c|c|c|c|c|c|}
\hline \multirow[b]{2}{*}{ Denek No } & \multicolumn{2}{|c|}{ Multipl doz 5-FU } & \multicolumn{2}{|c|}{ Tek doz 5-Fu } & \multicolumn{2}{|c|}{ Kontrol } \\
\hline & $\begin{array}{c}\text { Grup } 1 \\
\text { Multipl doz } \\
7 . \text { gün } \\
\end{array}$ & $\begin{array}{c}\text { Grup } 2 \\
\text { Multipl doz } \\
\text { 3.gün } \\
\end{array}$ & $\begin{array}{l}\text { Grup } 3 \\
\text { Tek doz } \\
7 . \text { gün } \\
\end{array}$ & $\begin{array}{l}\text { Grup } 4 \\
\text { Tek doz } \\
\text { 3.gün } \\
\end{array}$ & $\begin{array}{l}\text { Grup } 5 \\
\text { Kontrol } \\
7 . \text { gün } \\
\end{array}$ & $\begin{array}{l}\text { Grup } 6 \\
\text { Kontrol } \\
\text { 3.gün }\end{array}$ \\
\hline 1 & 1200 & 5200 & 13000 & 6800 & 35200 & 28200 \\
\hline 2 & 1500 & 2400 & 10800 & 6200 & 38200 & 28600 \\
\hline 3 & 800 & 5400 & 6400 & 6500 & 19600 & 32400 \\
\hline 4 & 2000 & 3200 & 14800 & 5300 & 22400 & 26000 \\
\hline 5 & 1600 & 2600 & 8900 & 5000 & 26000 & 35000 \\
\hline 6 & 1500 & 3800 & 10200 & 6200 & 24500 & 27500 \\
\hline 7 & 1000 & 2600 & 11200 & 5100 & 28300 & 32600 \\
\hline Ort $\pm S D$ & $\begin{array}{c}1371.4 \pm \\
373.07\end{array}$ & $\begin{array}{c}3600 \pm \\
1161.28\end{array}$ & $\begin{array}{c}10757.14 \pm \\
2516.15\end{array}$ & $\begin{array}{c}5871.42 \pm \\
671.27\end{array}$ & $\begin{array}{c}27742.86 \pm \\
6252.73\end{array}$ & $\begin{array}{c}30042.86 \pm \\
3046.24\end{array}$ \\
\hline
\end{tabular}

Üç ana grupta ortalama albumin değerleri (ort \pm SD) Grup 1 ve 2'de 2,6 ${ }^{2} 0,5$; Grup 3 ve

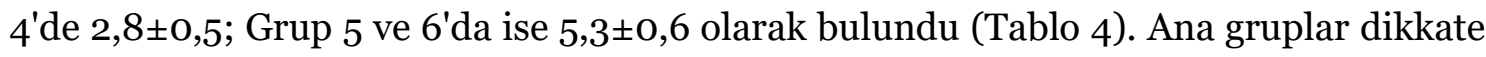
alınarak albumin değerleri karşılaştırıldığında; Grup 1 ve 2 ile Grup 5 ve 6 arasında ve Grup 3 ve 4 ile Grup 5 ve 6 arasinda anlamlı derecede istatistiksel fark bulundu (p<0.05). Ancak bu fark Grup 1 ve 2 ile Grup 3 ve 4 arasında bulunamadı (p>0,05) (Tek yönlüANOVA).

Albumin değerleri için; gruplar dikkate alındığında aralarındaki fark istatistiksel olarak anlamlı ( $<<0,05)$, sakrifiye edilen günler dikkate alındığında ise fark istatistiksel olarak anlamsız (p>0,05) bulundu (Çift yönlü-ANOVA). Albumin değerlerinde; kontrol gruplarına göre, 5-FU kullanılan gruplarda istatistiksel olarak anlamlı düşüşler tespit edildi.

Tablo 4: Grupların albumin değerleri (g/lt)

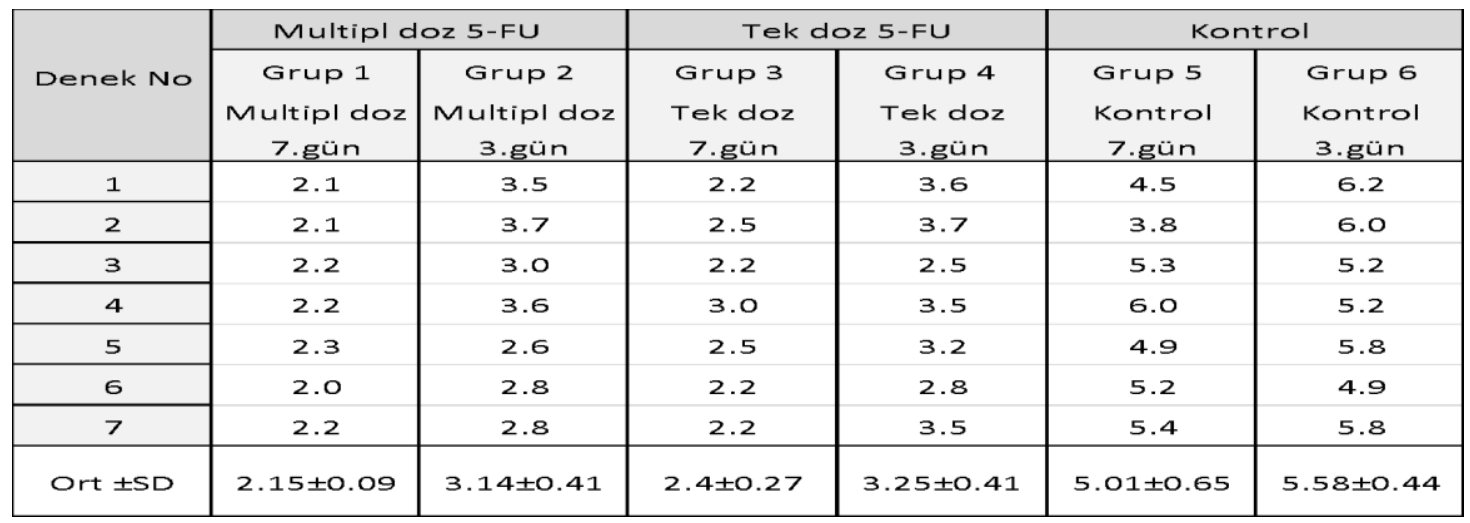


Ana gruplar dikkate alınarak hidroksiprolin değerleri açısından karşılaştırma yapıldığında; (Analysis of Variance) istatistiksel olarak anlamlı bir fark bulunamamıştır (p>0,05). Ancak gruplar içerisinde sakrifiye edilen günlere bağlı olarak gelişen değişikliklerdeki farklar istatistiksel olarak anlamlıdır ( $\mathrm{p}<0,05)$ (çift yönlü-ANOVA). 5FU'in kullanıldığı gruplar ile kontrol grupları arasında hidroksiprolin değerleri açısından bir fark bulunamazken, 7.gün değerlerinde tek doz grubu, multipl doz grubuna göre daha iyi skor elde etti (Tablo 5).

Tablo 5:Grupların hidroksiprolin değerleri (100 mg. kuru ağırlıkta dokuda/mg.)

\begin{tabular}{|c|c|c|c|c|c|c|}
\hline \multirow[b]{2}{*}{ Denek No } & \multicolumn{2}{|c|}{ Multipl doz 5-FU } & \multicolumn{2}{|c|}{ Tek doz 5-Fu } & \multicolumn{2}{|c|}{ Kontrol } \\
\hline & $\begin{array}{c}\text { Grup } 1 \\
\text { Multipl doz } \\
\text { 7.gün } \\
\end{array}$ & $\begin{array}{c}\text { Grup } 2 \\
\text { Multipl doz } \\
\text { 3.gün }\end{array}$ & $\begin{array}{l}\text { Grup } 3 \\
\text { Tek doz } \\
7 . g u ̈ n \\
\end{array}$ & $\begin{array}{c}\text { Grup } 4 \\
\text { Tek doz } \\
\text { 3.gün } \\
\end{array}$ & $\begin{array}{l}\text { Grup } 5 \\
\text { Kontrol } \\
7 . \text { gün }\end{array}$ & $\begin{array}{c}\text { Grup } 6 \\
\text { Kontrol } \\
\text { 3.gün }\end{array}$ \\
\hline 1 & 0.006 & 0.013 & 0.012 & 0.015 & 0.006 & 0.011 \\
\hline 2 & 0.011 & 0.011 & 0.007 & 0.018 & 0.049 & 0.008 \\
\hline 3 & 0.019 & 0.014 & 0.006 & 0.012 & 0.008 & 0.007 \\
\hline 4 & 0.015 & 0.033 & 0.011 & 0.013 & 0.012 & 0.010 \\
\hline 5 & 0.012 & 0.006 & 0.018 & 0.011 & 0.025 & 0.012 \\
\hline 6 & 0.008 & 0.010 & 0.022 & 0.009 & 0.044 & 0.013 \\
\hline 7 & 0.010 & 0.008 & 0.021 & 0.010 & 0.033 & 0.014 \\
\hline Ort $\pm S D$ & $0.0115 \pm 0.004$ & $\begin{array}{c}0.0135 \pm 0.0 \\
08\end{array}$ & $\begin{array}{c}0.0138 \pm 0.0 \\
06\end{array}$ & $\begin{array}{c}0.0125 \pm 0.0 \\
03\end{array}$ & $\begin{array}{c}0.0252 \pm 0.0 \\
17\end{array}$ & $\begin{array}{c}0.0107 \pm 0.0 \\
02\end{array}$ \\
\hline
\end{tabular}

Histopatolojik incelemede; preparatlarda eksüdasyon, makrofajlar, iltihabi infiltrasyon, vaskülarizasyon, fibroblast aktivitesi ve kollajen miktarı açısından skorlanma yapıldı. Her parametre sakrifiye edilen günlere göre iki ana gruba ayrllarak (3.gün, 7.gün) Kruskal Wallis (tek yönlü-ANOVA) yöntemi uygulanarak istatistiksel olarak incelendi. Mann-Whitney-U testi uygulanarak ise anlamlı fark bulunan parametrelerdeki değişim incelendi.

3.gün gruplarında; gruplar arasında istatistiksel anlamlı fark; eksüdasyon, iltihabi infiltrasyon ve makrofajlarda elde edildi $(\mathrm{p}<0,05)$. Diğer parametrelerdeki fark anlamsizdı ( $\mathrm{p}>0,05)$.

Eksüdasyon parametresinde; multipl doz grubu ile tek doz ve kontrol grupları arasında anlamlı fark bulunurken ( $\mathrm{p}<0.05$ ) tek doz grubu ile kontrol grubu arasında anlamlı fark yoktur. 
Eksüdasyonda; 3.gün preparatları incelendiğinde multipl doz uygulanan grupta anlamlı düzeyde daha yoğun bulundu. Bu da multipl doz grubunda, anastomoz iyileşmesinin diğer gruplara göre süre bakımından geri kaldığını göstermektedir. İltihabi infiltrasyon parametresinde, yalnız multipl doz grubu ile kontrol grubu arasında anlamlı fark bulundu $(\mathrm{p}<0,05)$. 3.günde iltihabi infiltrasyonun azalıp organizasyonun başlaması gerekirken, multipl doz grubunda organizasyon başlamamış, iyileşme süreç olarak geri kalmıştır. 3.günde makrofajlar incelendiğinde; multipl doz grubu ile tek doz grubu ve kontrol grupları arasında anlamlı fark bulundu ( $<<0,05)$. Multipl doz grubunda makrofajlar anlamlı düzeyde fazla bulundu. İyileşme olgusunun ilk günlerinde yüksek düzeye ulaşan makrofajlar üçüncü günde azalma eğilimi gösterirler. Bu sonuç, multipl doz grubunun iyileşme sürecinde geri kalmakta olduğunu göstermektedir. 3.günde tek doz grubu ile kontrol grubu arasında hiçbir parametre açısından anlamlı fark yoktur. Tek doz uygulanan 5-FU'in iyileşme üzerine negatif etkisi bulunmamıştır. Ancak elde edilen parametreler sonucu multipl doz 5-FU'in yara iyileşmesini geciktirdiği görülmüştür.

7.gün gruplarında; gruplar arasında istatistiksel anlamlı fark fibroblast aktivitesi, iltihabi infiltrasyon, makrofajlar ve kollajen miktarlarında elde edildi $(p<0,05)$. İltihabi infiltrasyon, makrofaj yoğunluğu 7.günde incelendiğinde tek doz grubunda anlamlı düzeyde düşük skor elde edildi, iyileşmenin erken geliştiğini kanıtladı. Fibroblast proliferasyonu ve kollajen formasyonu parametrelerinde de benzer şekilde tek doz grubunda anlamlı düzeyde yüksek skorlar elde edildi. Multipl doz grubunda ise kollajen formasyonu belirgin düzeyde zayıf görüldü. Vaskülarizasyon parametresinde de multipl doz grubunun daha zayıf olduğu gözlendi. 7.günde de tek doz uygulanan 5-FU'in yara iyileşmesi üzerine negatif etkisi olmadığı görüldü. Multipl doz 5-FU uygulamasının; iyileşme sürecinde olması gerekenden (kontrol grubundan) oldukça geri kaldı̆̆ı tespit edildi.

\section{Tartışma}

Küratif ameliyat yapılmasına karşın GİS kanserleri olguların \%85'inde sonradan lokal ve sistemik nüksler intraperitoneal implantasyon, hematojen ve lenfojen yayılıma bağlı görülmektedir ${ }^{25}$. Ameliyat sırasında travmaya bağlı olarak dökülen veya preoperatif saptanamayan periton içi serbest tümör hücreleri erken nükste rol oynadığ bilinmektedir ${ }^{25,26}$. Tüm kolon ve rektum kanserli hastalarda primer tümör rezeksiyonu 
sırasında ortalama \%10 peritoneal yayılım olduğu kabul edilmektedir ${ }^{27}$. Sugarbaker ve $\operatorname{arkadaşları}^{28}$ kolorektal kanserli hastalarda lümen içi tümör hücrelerinin \%30 oranında anastomoz sınırında nüks meydana getirdiğini saptamışlardır.

Gastrointestinal sistemin özellikle 5-FU kullanımına duyarlı olduğu, deneysel çalışmalarda epitelyal mitotik aktiviteyi yavaşlattığı gösterilmiştir²9. Günümüzde kolorektal kanserin kemoterapisinde 5-FU başlıca sitostatik madde olarak kabul edilmektedir14,16,29-31. Ancak 5-FU'in sistemik kullanımı sonrası zararlı yan etkilerin önlenmesi amacı ile intraperitoneal kemoterapi gündeme gelmiştir ${ }^{28}$. Archer ve

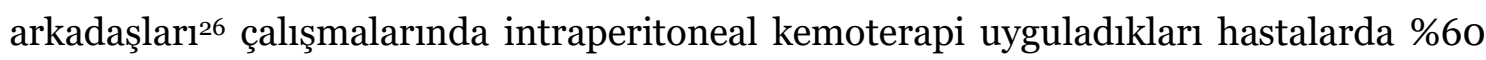
oranında yaşam süresi uzaması tespit etmişler ve intraperitoneal kemoterapinin sistemik

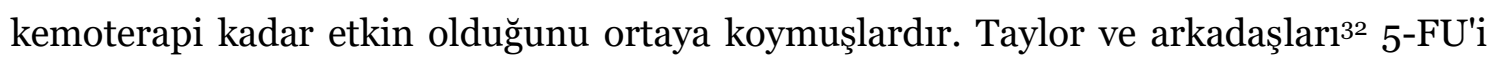
kolorektal kanserli hastalarda intraperitoneal olarak kullanmış ve beş yıllık yaşam süresinin \%30 oranında uzadığını göstermişlerdir.

İntraperitoneal kemoterapide kemoterapötik ajanın büyük moleküllü olması, suda erime özelliğinin ve hücreye penetrasyon gücünün fazla olması aranan özellikler olarak belirlenmiştir. İntraperitoneal sitostatik ajan olan 5-FU uygulanmasında, ilacın plazma konsantrasyonlarının çok düşük olması nedeni ile toksik etkileri olarak, orta derecede kilo kaybı ve beyaz kan hücrelerinde geçici azalma bildirilmiştir. Dinççağ ve arkadaşları ${ }^{25}$ 5-FU'i deneysel çalışmalarında $20 \mathrm{mg} / \mathrm{kg}$ günlük doz olarak tavsiye etmişlerdir. DeWaard ve arkadaşları ${ }^{14}$ ise 5 -FU'i aynı dozda intraperitoneal olarak kullanmışlardır. Geleneksel $20 \mathrm{mg} / \mathrm{kg} /$ gün düzeyinde 5 -FU dozun aksine Goldman ve arkadaşları ${ }^{29}$ deneysel çalışmalarında 5-FU'in günlük intraperitoneal dozunun $25 \mathrm{mg} / \mathrm{kg}$ olduğunu savunmuşlardır. Berberoğlu ve arkadaşları ise ${ }^{16} 5$-FU'i $180 \mathrm{mg} / \mathrm{kg}$ intraperitoneal tek doz uygulamışlardır. Çalışmada 5-FU'i alışılageldiği gibi $20 \mathrm{mg} / \mathrm{kg}$ intraperitoneal günlük dozda uygulanmıştır. Multipl uygulamalarda ise birbirini takip eden üç gün aynı şekilde $20 \mathrm{mg} / \mathrm{kg} /$ gün intraperitoneal doz uygulanmıştır.

5-FU ve analoglarının kullanımındaki çeşitli yan etkiler ilacın farklı dozlarda ortaya çıkan hematolojik toksitesine bağlanabilir. Goldman ve arkadaşları ${ }^{29}$ yaptıkları deneysel çalışmada sıçanlarda 5-FU'i bir ile beş günlük tedavi süreleri içerisinde kullanmışlar, hematolojik toksisite olarak doza bağlı olarak düşen lökosit değerleri tespit etmişlerdir. De Waar ve arkadaşları ${ }^{14}$, Erdener ve arkadaşları33, Graf ve arkadaşları ${ }^{31}$ aynı şekilde; 
yaptıkları deneysel çalışmalarda 5-FU uygulaması sonrası lökosit değerlerinde anlamlı düşmeler göstermişlerdir. Bu çalışmada, 5-FU'in tek doz ve multipl doz kullanılan gruplarında, kontrol gruplarına göre lökosit değerlerinde istatistiksel olarak anlamlı düşük değerler tespit edilmiştir ( $\mathrm{p}<0,05)$. Ancak lökosit değerlerinde gruplar açısından anlamlı farklar bulunmasına karşın, sakrifiye edilen günler açısından değerlendirildiğinde anlamlı farklar bulunamamıştır ( $p>0,05)$.

Klinik çalışmaların bir kısmında ise 5-FU ile yara onarımının sağlıksız ve geç olacağı, yara ile ilgili komplikasyonların artacağı, bu nedenle tedaviye postoperatif 15 . günden sonra başlanması gerektiği bildirilmiştir ${ }^{6,16}$. Öte yandan klinik uygulamada, ameliyat sırasında dolaşıma, barsak lümenine, peritoneal kaviteye dökülen tümör hücrelerinin erkenden yok edilmesi amacı ile erken postoperatif dönemde intraperitoneal 5 -FU verilmesinin zararlı etkisi olmayacağını savunanlarda mevcuttur ${ }^{6,7}$. Çalışmada intraperitoneal 5-FU'in yara iyileşmesi üzerindeki etkilerini incelemek amacı ile anastomoz hattındaki dokuda albümin ve hidroksiprolin değerlerini karşılaştılmıştır. Albumin değerleri incelendiğinde tek ve multipl doz 5-FU kullanılan gruplar ile kontrol grupları arasında istatistiksel olarak anlamlı düşük değerler tespit edilmiştir ( $p<0,05)$. Graf ve arkadaşları ${ }^{31}$ deneysel çalışmalarında 5-FU'i tek başına ve folinik asit ile birlikte kullanmışlar ve her iki grupta da serum albumin değerlerinde düşme kaydetmişlerdir. Erdener ve arkadaşları ise ${ }^{33}$ çalışmalarında total protein değerlerini kontrol etmişler, ancak anlamlı bir fark gözlemlememişlerdir.

Çalışmada 5-FU grupları ile kontrol grupları arasında karşılaştırılan hidroksiprolin düzeylerinde elde edilen değerler arasında anlamlı istatistiksel farklar bulunmamıştır (p>0,05). Gruplar içerisinde sakrifiye edilen günlere bağlı olarak gelişen değişikliklerdeki farklar istatistiksel olarak anlamlıdır ( $p>0,05)$. Bu sonuçlar literatüre uygunluk göstermektedir31. Goldman ve arkadaşları $^{29}$ deneysel çalışmalarında postoperatif erken dönemde kullanılan 5-FU'in negatif etkilerinin doza bağlı olarak değiştiğini göstermişlerdir. Artan doz ile anastomoz kaçağı ve buna bağlı peritonit tablosunun deneklerin ölümüne yol açtığını belirtmişlerdir. Berberoğlu ve arkadaşları ${ }^{16}$ yaptıkları deneysel çalışmada 5-FU'in intraoperatif ve erken postoperatif dönemde uygulanmasının yara iyileşmesini olumsuz yönde etkilemediğini belirtmişlerdir. DeWaard ve arkadaşları da ${ }^{14}$ benzer şekilde deneysel çalışmalarında, erken postoperatif 5-FU'in intestinal anastomozlar üzerindeki etkisini araştırmış ve sınırlı dozlarda 
kullanım şartı ile 5-FU'in erken postoperatif dönemde anastomoz sağlığını bozmadığını göstermiştir.

Bu çalışmada literatüre uyumlu olarak tek doz 5-FU uygulanan grupta, multipl doz 5-FU uygulanan gruba göre olumlu sonuçlar elde edilmiştir. Tek doz grubunun parametreleri incelendiğinde kontrol grubuna göre istatistiksel düzeyde anlamlı değişiklikler elde edilmemiştir ( $\mathrm{p}>0,05)$. Bu histopatolojik bulgular, patlama basıncı ve hidroksiprolin düzeyi sonuçlarına uygunluk göstermekte olup, tek doz 5-FU uygulamasında anastomoz iyileşmesinde negatif etki görülmezken, multipl doz 5-FU uygulanmasının anastomoz iyileşme sürecinde uzamaya neden olduğunu göstermektedir.

\section{Sonuç}

$\mathrm{Bu}$ çalışmada anastomoz patlama basıncı, hidroksiprolin miktarı ve anastomoz bölgesinin histopatolojik değerlendirme kriterlerini göz önüne alındığında, düşük dozlarda (tek doz) intraperitoneal 5-FU uygulamasının literatürle uyumlu olarak deneysel kolon anastomoz iyileşmesini olumsuz yönde etkilemediği görülmüştür. Her ne kadar deneysel çalışma sonuçları klinik uygulamalar için ancak yol gösterici özellik taşısa da sonuçlar, erken postoperatif dönemde intraperitoneal 5-FU ile kemoterapiyi klinik uygulamada faydalanılabilir bir yöntem olarak gündeme getirmektedir.

\section{KAYNAKLAR}

1. Cunliffe WJ, Sugarbaker PH. Gastrointestinal malignancy: rationale for adjuvant therapy using early postoperative intraperitoneal chemotherapy. British Journal of Surgery. 1989;76(10):1082-1090. doi:10.1002/bjs.1800761030.

2. Hillan K, Nordlinger B, Ballet F, Puts JP, Infante R. The healing of colonic anasto-moses after early intraperitoneal chemotherapy: an experimental study in rats. Journal of Surgical Research. 1988;44(2):166-171. doi:10.1016/00224804(88)90045-5.

3. Hohenberger P, Schlag P, Schwarz V, Herfarth C. Tumor recurrence and options for further treatment after resection of liver metastases in patients with 
colorectal cancer. Journal of Surgical Oncology. 1990;44(4):245-251. doi:10.1002/jso.2930440411.

4. Metzger U, Mermillod B, Aeberhard P, et al. Intraportal chemotherapy in colorectal carcinoma as an adjuvant modality. World Journal of Surgery. 1987;11(4):452-458. doi:10.1007/BF01655809.

5. Sugarbaker PH, Gianola FJ, Barofsky I, Hancock SL, Wesley R. 5-Fluorouracil chemotherapy and pelvic radiation in the treatment of large bowel cancer. Decreased toxicity in combined treatment with 5 -fluorouracil administration through the intraperitoneal route. Cancer. 1986;58(4):826-831. doi:10.1002/1097-0142(19860815)58:4<826::aid-cncr2820580403>3.0.co;2-o.

6. Falcone RE, Nappi JF. Chemotherapy and wound healing. Surgical Clinics of North America. 1984;64(4):779-794. doi:10.1016/s0039-6109(16)43394-3.

7. Klausner JM, Lelcuk S, Inbar M, Rozin R. The effects of perioperative fluorouracil administration on convalescence and wound healing. Archives of Surgery. 1986;121(2):239-242. doi:10.1001/archsurg.1986.01400020125017.

8. Nissen-Meyer R, Kjellgren K, Malmio K, Månsson B, Norin T. Surgical adjuvant chemotherapy: results with one short course with cyclophosphamide after mastectomy for breast cancer. Cancer. 1978;41(6):2088-2098. doi:10.1002/1097-0142(197806)41:6<2088::aid-cncr2820410604>3.0.co;2-j.

9. Haskel CM. Principles of cancer chemotherapy in: cancer treatment. 2nd ed. Philadelphia: WB Saunders Co.; 1985.

10. Cohn I Jr. Complications and toxic manifestations of surgical adjuvant chemotherapy for breast cancer. Surgery, Gynecology and Obstetrics. 1968;127(6):1201-1209.

11. Lawrence WT, Talbot TL, Norton JA. Preoperative or postoperative doxorubicin hydrochloride (adriamycin): which is better for wound healing? Surgery. 1986;100(1):9-13.

12. Cohen SC, Gabelnick HL, Johnson RK, Goldin A. Effects of antineoplastic agents on wound healing in mice. Surgery. 1975;78(2):238-244.

13. De Roy van Zuidewijn DB, Wobbes T, Hendriks T, Klompmakers AA, de Boer HM. The effect of antineoplastic agents on the healing of small intestinal 
anastomoses in the rat. Cancer. 1986;58(1):62-66. doi:10.1002/10970142(19860701)58:1<62::aid-cncr2820580112>3.0.co;2-x.

14. De Waard JW, Wobbes T, Hendriks T. Early post-operative 5-fluorouracil does not affect the healing of experimental intestinal anastomoses. International Journal of Colorectal Disease. 1993;8(3):175-178. doi:10.1007/BFo0341194.

15. Fumagalli U, Trabucchi E, Soligo M, et al. Effects of intraperitoneal chemotherapy on anastomotic healing in the rat. Journal of Surgical Research. 1991;50(1):82-87. doi:10.1016/0022-4804(91)90014-d

16. Berberoğlu U, Erekul S, Akbay C, Sayın N, Töral D, Sezerdoğdu V. Antimetabolit grubu kemoterapötiklerin yara iyileşmesine etkileri. Ulusal Cerrahi Dergisi. 1989;5(3):11-14.

17. Matheson NA, Irving AD. Single layer anastomosis in the gastrointestinal tract. Surgery, Gynecology and Obstetrics. 1976;143(4):619-624.

18. Jiborn H, Ahonen J, Zederfeldt B. Healing of experimental colonic anastomoses. The effect of suture technic on collagen concentration in the colonic wall. American Journal of Surgery . 1978;135(3):333-340. doi:10.1016/00029610(78)90062-4.

19. Weiber S, Jiborn H, Zederfeldt B. Preoperative irradiation and colonic healing. European Journal of Surgery. 1994;160(1):47-51.

20. Beahrs OH. Continent ileostomy and ileoanal procedures. Surgical Clinics of North America. 1986;66(4):833-839. doi:10.1016/soo39-6109(16)43994-0.

21. Rousselot LM, Slattery JR. Immediate complications of surgery of the large intestine. Surgical Clinics of North America. 1964;44:397-410. doi:10.1016/soo39-6109(16)37238-3.

22. Goligher JC, Graham NG, De Dombal FT. Anastomotic dehiscence after anterior resection of rectum and sigmoid. British Journal of Surgery. 1970;57(2):109118. doi:10.1002/bjs.1800570208.

23. Morgenstern L, Yamakawa T, Ben-Shoshan M, Lippman H. Anastomotic leakage after low colonic anastomosis. Clinical and experimental aspects. American Journal of Surgery. 1972;123(1):104-109. doi:10.1016/00029610(72)90317-0. 
24. Matheson NA, Irving AD. Single layer anastomosis after rectosigmoid resection. British Journal of Surgery. 1975;62(3):239-242. doi:10.1002/bjs.1800620318. 25. Dinççă̆ A, Erbil Y, Şerbetçioğlu A, Bozbora A, Özarmağan S, Mercan S. İntraperitoneal kemoterapi. Çağdaş Cerrahi Dergisi. 1993;7:98-100.

26. Archer S, Gray B. Intraperitoneal 5-fluorouracil infusion for treatment of both peritoneal and liver micrometastases. Surgery. 1990;108(3):502-507.

27. Sugarbaker PH. Intraperitoneal chemotherapy for treatment and prevention of peritoneal carcinomatosis and sarcomatosis. Diseases of the Colon and Rectum. 1994;37(2):115-122. doi:10.1007/BFo2048443.

28. Sugarbaker PH, Gianola FJ, Speyer JC, Wesley R, Barofsky I, Meyers CE. Prospective, randomized trial of intravenous versus intraperitoneal 5fluorouracil in patients with advanced primary colon or rectal cancer. Surgery. 1985;98(3):414-422.

29. Goldman LI, Lowe S, al-Saleem T. Effect of fluorouracil on intestinal anastomoses in the rat. Archives of Surgery. 1969;98(3):303-304. doi:10.1001/archsurg.1969.01340090079011.

30. Graf W, Ivarsson M, Gerdin B, Hellsing K, Påhlman L, Glimelius B. The influence of early postoperative intraperitoneal chemotherapy on human wound healing. Journal of Surgical Research. 1994;57(3):394-400. doi:10.1006/jsre.1994.1160.

31. Graf W, Weiber S, Glimelius B, Jiborn H, Påhlman L, Zederfeldt B. Influence of 5-fluorouracil and folinic acid on colonic healing: an experimental study in the rat. British Journal of Surgery. 1992;79(8):825-828. doi:10.1002/bjs.1800790840.

32. Taylor I, Machin D, Mullee M, Trotter G, Cooke T, West C. A randomized controlled trial of adjuvant portal vein cytotoxic perfusion in colorectal cancer. British Journal of Surgery. 1985;72(5):359-363. doi:10.1002/bjs.1800720509.

33. Erdener A, Çetinkurşun S, Avanoğlu A ve ark. İntraperitoneal adjuvan 5-DFUR' in siçan kolon anastomozunda iyileşmeye etkisi. Ulusal Cerrahi Dergisi. 1990;6(3):25-27. 